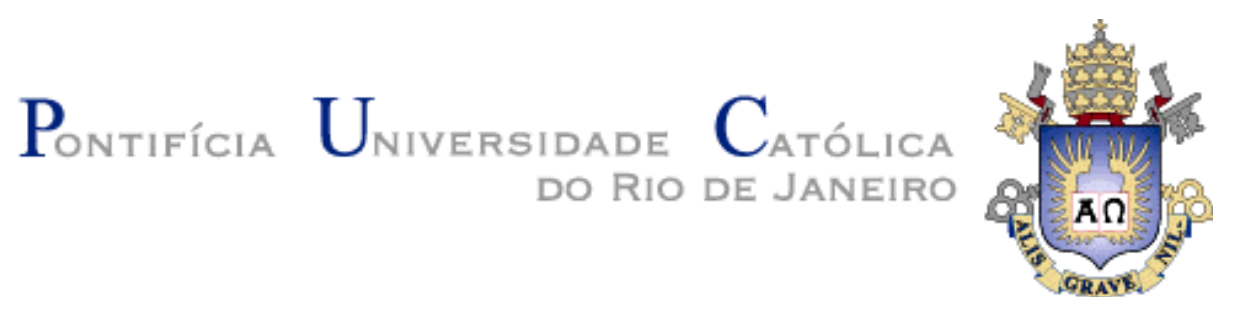

Marina Dias de Faria

\title{
Pessoas com Deficiência Visual e Consumo em Restaurantes: Um Estudo Utilizando Análise Conjunta
}

\section{Dissertação de Mestrado}

Dissertação apresentada ao Programa de Pósgraduação em Administração de Empresas da PUC-Rio como requisito parcial para obtenção do titulo de Mestre em Administração de Empresas.

Orientador: Prof. Jorge Ferreira da Silva

Rio de Janeiro Outubro de 2010 


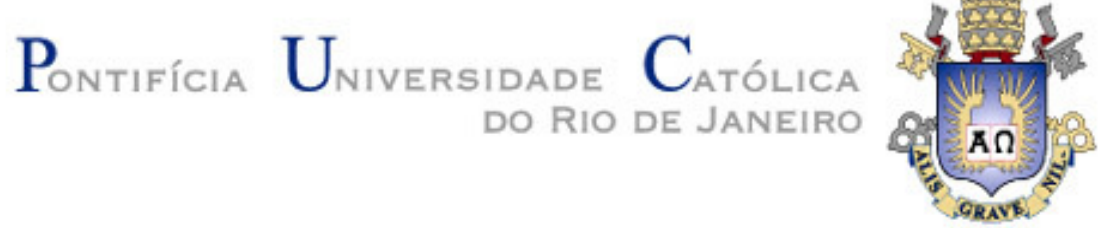

Marina Dias de Faria

\section{Pessoas com Deficiência Visual e Consumo em Restaurantes: Um Estudo Utilizando Análise Conjunta}

Dissertação apresentada como requisito parcial para obtenção do grau de Mestre pelo Programa de Pós-graduação em Administração de Empresas da PUC-Rio. Aprovada pela Comissão Examinadora abaixo assinada.

Prof. Jorge Ferreira da Silva

Orientador

Departamento de Administração - PUC-Rio

Prof ${ }^{a}$. Angela Maria Cavalcanti da Rocha

Departamento de Administração - PUC-Rio

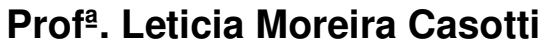

UFRJ

Profa. Mônica Herz

Vice-Decana de Pós-Graduação do CCS

Rio de Janeiro, 5 de outubro de 2010 
Todos os direitos reservados. É proibida a reprodução total ou parcial do trabalho sem autorização da universidade, da autora e do orientador.

\section{Marina Dias de Faria}

Graduou-se em Administração na Universidade Federal do Rio de Janeiro (UFRJ) em 2008. Desenvolve pesquisas acadêmicas principalmente focadas em consumidores com deficiência.

Ficha Catalográfica

\section{Faria, Marina Dias de}

Pessoas com deficiência visual e consumo em restaurantes: um estudo utilizando análise conjunta / Marina Dias de Faria ; orientador: Jorge Ferreira da Silva. -2010. 180 f. : il. (color.) ; $30 \mathrm{~cm}$

Dissertação (mestrado)-Pontifícia Universidade Católica do Rio de Janeiro, Departamento de Administração, 2010.

Inclui bibliografia

1. Administração - Teses. 2. Comportamento do consumidor. 3. Pessoas com deficiência visual. 4. Análise conjunta. 5. Marketing de serviços. 6. Restaurantes. 7. Serviços de lazer. 8. Acessibilidade. I. Silva, Jorge Ferreira da. II. Pontifícia Universidade Católica do Rio de Janeiro. Departamento de Administração. III. Título. 
Para a minha mãe, Lúcia, e o meu namorado, Zeca, pelo amor e confiança. 


\section{Agradecimento}

Ao Prof. Jorge Ferreira da Silva que me orientou nessa dissertação sempre com muito carinho e dedicação.

Às professoras Angela da Rocha e Letícia Casotti que participaram da banca examinadora.

Aos professores e funcionários da PUC-Rio que me ajudaram durante todo o mestrado.

À Ethel Rosenfeld pela sua ajuda que foi fundamental para a execução dessa dissertação.

A todos os participantes das etapas empíricas da pesquisa, especialmente aqueles que cederam suas casas para a realização dos grupos de foco.

Aos funcionários do Instituto Benjamin Constant que foram sempre muito gentis e prestativos me auxiliando na realização da parte empírica da pesquisa.

À minha mãe por todo apoio e carinho não só durante o mestrado, mas em todos os momentos da minha vida.

Ao meu namorado Zeca pelo carinho, apoio e pelas intermináveis conversas sobre assuntos acadêmicos. 


\section{Resumo}

Faria, Marina Dias de; Silva, Jorge Ferreira da. Pessoas com Deficiência Visual e Consumo em Restaurantes: Um Estudo Utilizando Análise Conjunta. Rio de Janeiro, 2010. 180p. Dissertação de Mestrado Departamento de Administração, Pontifícia Universidade Católica do Rio de Janeiro.

O presente estudo teve como objetivo principal determinar a importância relativa que as pessoas com deficiência visual dão aos atributos do serviço de restaurantes em momentos de lazer e a utilidade associada por tais consumidores aos níveis desses atributos. Para atingir esse objetivo, a parte empírica da pesquisa foi dividida em três etapas. Na primeira foram conduzidos grupos de foco com o objetivo de identificar os principais atributos de serviços e seus níveis para deficientes visuais em restaurantes. Na Etapa 2 foi aplicado um questionário e, com os resultados dessa survey, se passou à análise conjunta. Na Etapa 3 foram feitas observações e conduzidas entrevistas em restaurantes do Rio de Janeiro, visando verificar se os fatores apontados como mais relevantes para as pessoas com deficiência visual estão presentes em tais estabelecimentos. Os resultados da pesquisa apontaram cinco atributos como sendo os mais importantes: a ambiência, $\mathrm{o}$ atendimento, o formato da mesa, o acesso ao garçom e o cardápio. $\mathrm{O}$ acesso ao garçom teve a maior importância relativa, e o nível desse atributo com maior utilidade parcial foi o botão para chamar o garçom por meio de uma campainha. Foi possível identificar três clusters segmentando as pessoas com deficiência visual de acordo com as preferências relativas ao consumo em restaurantes. A terceira etapa mostrou que os restaurantes não são acessíveis. É necessário que invistam em mudanças de infra-estrutura e treinamento dos funcionários para que possam atender os consumidores com deficiência. Ao final são apontadas sugestões para estudos futuros e recomendações para praticantes.

\section{Palavras-chave}

Comportamento do consumidor; pessoas com deficiência visual; análise conjunta; marketing de serviços; restaurantes; serviços de lazer; acessibilidade 


\section{Abstract}

Faria, Marina Dias de; Silva, Jorge Ferreira da (Advisor). VisuallyImpaired People and Consumption in Restaurants: A Conjoint Analysis Study. Rio de Janeiro, 2010, 180 p. MSc Dissertation. Departamento de Administração, Pontifícia Universidade Católica do Rio de Janeiro.

The main objective of the present study was to determine the relative importance given by visually-impaired people to the service attributes of restaurants as experienced during their leisure time, along with the respective associated utility of the services, as they were perceives by these users. In order to accomplish that, the empirical aspect of the research was divided in three stages. Focus groups were conducted in stage one, aiming to identify the primary service attributes and their levels regarding visually-impaired costumers in restaurants. On stage two a questionnaire was used and the results of this survey led to the conjoint analysis. Field observations and interviews were applied in restaurants in Rio de Janeiro during stage three with the intention to verify whether or not factors elected as being of greater importance to visually-impaired people were present in such restaurants. The results obtained with the research point to five attributes as the most important: the overall ambiance, costumer service, table configuration, access to service, and the menu. Access to service had the greater relative importance. The level of this particular attribute with higher partial utility was the button that triggers the buzzer. Furthermore, it was possible to identify three clusters that group visually-impaired people according to their relative preferences toward restaurant consumption habits. Stage three showed that restaurants are not accessible; infrastructure changes and staff training are necessary to accommodate visually-impaired consumers' needs. The final chapter addresses suggestions for future studies, as well as recommendations for practitioners.

\section{Keywords}

Consumer behaviour; visually-impaired people; conjoint analysis; marketing Services; restaurants; leisure services; accessibility 


\section{Sumário}

1. Introdução 15

1.1. Justificativa 15

1.2. Delimitação do problema 17

$\begin{array}{ll}\text { 1.3. Objetivo da pesquisa } & 19\end{array}$

2. Revisão de literatura 22

2.1 Serviços de lazer $\quad 22$

2.2 Pessoas com deficiência $\quad 24$

2.3 Pessoas com deficiência no papel de consumidores 27

2.4 Consumo de serviços de lazer por pessoas com deficiência 33

2.5 Restaurantes como ambientes de lazer 36

2.6 Estratégias empresariais para atender pessoas com 39

deficiência

3. Metodologia 43

3.1 Panorama da pesquisa empírica 43

3.2 Etapa 1- Grupo de foco $\quad 45$

3.2.1 Seleção dos sujeitos da Etapa 1

3.2.2 Coleta de dados da Etapa $1 \quad 47$

3.2.3 Tratamento da dados da Etapa $1 \quad 50$

3.3 Etapa 2- Survey 52

3.3.1 População e amostra da Etapa 2

3.3.2 Coleta de dados da Etapa $2 \quad 56$

3.3.3 Tratamento de dados da Etapa $2 \quad 58$

3.4 Etapa 3- Observação e entrevistas 60

3.4.1 Seleção de sujeitos da Etapa $3 \quad 60$

3.4.2 Coleta de dados da Etapa $3 \quad 62$

3.4.3 Tratamento de dados da Etapa $3 \quad 63$

3.5 Limitações do método $\quad 63$

4. Resultados 66

4.1 Resultados da Etapa $1 \quad 66$

4.1.1 Apresentação e análise dos resultados dos grupos de foco 66

4.1.1.1 Vamos comer fora? Onde? No restaurante de sempre! 66

4.1.1.2 Posso "ver" o cardápio?!?! 68

4.1.1.3 Será que alguém saberia me atender aqui? 70

4.1.1.4 Ambiente perfeito para mim: Eu só que sossego! 72

4.1.1.5 Sobre mesas retangulares e redondas... 73

4.1.1.6 Garçom! Pode vir aqui? Garçom... 75

4.1.1.7 Tem muita gente aqui! Melhor assim?!?! 76

4.1.1.8 Onde fica? No shopping ou na rua? 78

4.1.1.9 Eu vim aqui só para comer. E a comida? 79

4.1.1.10 Como chego ao banheiro? Difícil me movimentar, falta sinalização $\quad 80$

4.1.2 Atributos e níveis identificados $\quad 82$

4.1.3 Resultado do projeto fatorial fracionado $\quad 87$

$\begin{array}{ll}4.2 \text { Resultados da Etapa } 2 & 91\end{array}$ 
4.2.1 Resultados da análise da amostra total 92

4.2.2 Resultados das análises comparativas 102

4.2.2.1 Gênero 102

4.2.2.2 Cegueira congênita ou adquirida 106

4.2.2.3 Mora sozinho ou acompanhado 112

4.2.2.4 Faixa etária 115

4.2.2.5 Trabalha no momento ou não trabalha 120

4.2.2.6 Renda 124

4.2.2.7 Frequenta restaurantes com amigos com deficiência visual $\quad 127$

4.3.2 Resultado da análise de cluster $\quad 131$

4.3 Resultados da Etapa 3 135

4.3.1 Infraestrutura acessível 136

4.3.2 Aspectos do atendimento 139

5 Conclusão 141

5.1 Considerações finais 141

5.2 Contribuições para praticantes 146

5.3 Sugestões para estudos futuros 149

Referências Bibliográficas $\quad 154$

ANEXO 1- Questionário 177

ANEXO 2- Autorização para pesquisa no IBC 180 


\section{Lista de Figuras}

Figura 1 - Restaurante acessível $\quad 39$

Figura 2 - Esquema da parte empírica da pesquisa $\quad 45$ 


\section{Lista de Gráficos}

Gráfico 1- Caracterização da amostra da Etapa 2: 53

Deficiência congênita $X$ adquirida

Gráfico 2- Caracterização da amostra da Etapa 2: Gênero 53

Justificativa

Gráfico 3- Caracterização da amostra da Etapa 2: Mora sozinho? 53

Gráfico 4- Caracterização da amostra da Etapa 2: Rendo Familiar 54

Gráfico 5- Caracterização da amostra da Etapa 2: 54

Trabalhando no momento

Gráfico 6- Caracterização da amostra da Etapa 2: Faixa Etária 54

Gráfico 7- Caracterização da amostra da Etapa 2: Momentos que 55

mais frequenta restaurantes

Gráfico 8- Caracterização da amostra da Etapa 2: Companha em 55

momentos de lazer em restaurantes

Gráfico 9- Caracterização da amostra da Etapa 2: Frequência em 56

restaurantes em momentos de lazer

Gráfico 10 - Importância dos atributos 96

Gráfico 11 - Utilidades Parciais dos níveis do atributo 97

"acesso ao garçom"

Gráfico 12 - Utilidades Parciais dos níveis do atributo "ambiência" 98

Gráfico 13 - Utilidades Parciais dos níveis do atributo "formato da mesa"

99

Gráfico 14 - Utilidades Parciais dos níveis do atributo "cardápio" 101

Gráfico 15 - Utilidades Parciais dos níveis do atributo

"atendimento" 102

Gráfico 16 - Utilidades Parciais dos níveis do atributo "cardápio" 110

Gráfico 17 - Utilidades Parciais dos níveis do atributo "formato da mesa"

Gráfico 18 - Utilidades Parciais dos níveis do atributo "cardápio" 123

Gráfico 19 - Utilidades Parciais dos níveis do atributo "cardápio" 130 


\section{Lista de Tabelas}

Tabela 1- Tipos de deficiência por sexo 25

Tabela 2 - Caracterização dos participantes dos grupos de foco $\quad 47$

Tabela 3- Resultado do projeto fatorial fracionado $\quad 51$

Tabela 4 - Amostra da Etapa $3 \quad 61$

Tabela 5 - Atributos e níveis selecionados na Etapa $1 \quad 87$

Tabela 6 - Características para segmentação $\quad 92$

Tabela 7- Correlação geral 93

Tabela 8- Utilidades e preferências $\quad 94$

Tabela 9 - Utilidades parciais e importâncias relativas 96

Tabela 10 - Correlação para os respondentes do sexo masculino 103

Tabela 11 - Correlação para os respondentes do sexo feminino 103

Tabela 12- Utilidades e preferências 104

Tabela 13- Utilidades parciais e importâncias relativas segmentada por gênero 105

Tabela 14 - Teste de Mann-Whitney U de igualdade de 106

médias para o atributo "acesso ao garçom"

Tabela 15 - Teste Mann-Whitney U de igualdade de médias para

o atributo "ambiência" 106

Tabela 16 - Correlação para os respondentes com cegueira 107 congênita

Tabela 17 - Correlação para os respondentes com cegueira adquirida

Tabela 18- Utilidades e preferências

107

Tabela 19 - Utilidades parciais e importâncias relativas

segmentada por gênero

Tabela 20 - Teste de Mann-Whitney $U$ de igualdade de médias para os níveis do atributo "cardápio"

Tabela 21 - Teste de Mann-Whitney U de igualdade de médias para os níveis do atributo "formato da mesa"

Tabela 22 - Teste de Mann-Whitney U de igualdade de médias para todos os atributos

Tabela 23 - Correlação para os respondentes que moram sozinhos

Tabela 24 - Correlação para os respondentes que

não moram sozinhos

Tabela 25- Utilidades e preferências

109

110

111

111

111

112

112

114

Tabela 26 - Utilidades parciais e importâncias relativas

segmentadas por pessoas que moram sozinhas e pessoas que não moram sozinhas

Tabela 27- Teste de Mann-Whitney U de igualdade de médias

para os atributos "formato da mesa" e "cardápio"

Tabela 28 - Correlação para os respondentes com até 25 anos 116

Tabela 29 - Correlação para os respondentes de 26 até 45 anos 116

Tabela 30 - Correlação para os respondentes de 45 até 55 anos 116

Tabela 31 - Correlação para os respondentes com mais de 55 anos

Tabela 32- Utilidades e preferências 
Tabela 33- Utilidades parciais e importâncias relativas

segmentadas por faixa etária

Tabela 34- Correlação para os respondentes não empregados 120

Tabela 35- Correlação para os respondentes empregados 120

Tabela 36- Utilidades e preferências 122

Tabela 37- Utilidades parciais e importâncias relativas

segmentada por empregado no momento ou não

Tabela 38- Teste de Mann-Whitney $U$ de igualdade de médias para os níveis do atributo "cardápio"

Tabela 39 - Teste de Mann-Whitney $U$ de igualdade de médias para todos os atributos

Tabela 40- Correlação para os respondentes das classes C e D 124

Tabela 41- Correlação para os respondentes das classes A e B $\quad 125$

Tabela 42- Utilidades e preferências

Tabela 43- Utilidades parciais e importâncias relativas segmentada por renda

Tabela 44 - Correlação para os respondentes que freqüentam restaurantes com amigos com deficiência

Tabela 45 - Correlação para os respondentes que não freqüentam restaurantes com amigos com deficiência

Tabela 46- Utilidades e preferências

Tabela 47- Utilidades parciais e importâncias relativas segmentadas por respontes que freqüentam restaurantes com amigos diecientes e os que nâo freqüentam

Tabela 48-Teste de Mann-Whitney $U$ de igualdade de médias para os níveis do atributo "cardápio"

Tabela 49 -Teste de Mann-Whitney $U$ de igualdade de médias para todos os atributos

Tabela 50 - Resultados das aglomerações da clusterização hierárquica

Tabela 51 - Variações do coeficiente de aglomeração

Tabela 52 - Casos por cluster

Tabela 53 - Teste Kruskal-Wallis para todos os níveis para os diferentes clusters

Tabela 54 - Médias das utilidades parciais dos níveis por cluster

Tabela 55 - Matriz de possibilidades para estudos futuros 
"Impaciente espero no escuro Que a noite acabe, que o perigo cesse, Que se cale a voz do preconceito." Black-Out

Virgínia Vendramini (poetisa deficiente visual e participante da pesquisa)

"É com o coração que se vê corretamente. O essencial é invisivel aos olhos." O Pequeno Príncipe Antoine de Saint-Exupéry 